\title{
Comparison of Steady and Transient Flow Boiling Critical Heat Flux for FeCrAl Accident Tolerant Fuel Cladding Alloy, Zircaloy, and Inconel
}

Soon Lee, Maolong Liu, Nicholas Brown, Kurt Terrani, Edward Blandford, Heng Ban, Colby B Jensen, Youho Lee

April 2019

The INL is a U.S. Department of Energy National Laboratory operated by Battelle Energy Alliance

Idaho National Laboratory 


\section{Comparison of Steady and Transient Flow Boiling Critical Heat Flux for FeCrAl Accident Tolerant Fuel Cladding Alloy, Zircaloy, and Inconel}

Soon Lee, Maolong Liu, Nicholas Brown, Kurt Terrani, Edward Blandford, Heng Ban, Colby B Jensen, Youho Lee

April 2019

Idaho National Laboratory Idaho Falls, Idaho 83415

http://www.inl.gov

Prepared for the

U.S. Department of Energy

Under DOE Idaho Operations Office

Contract DE-AC07-05ID14517 


\section{Comparison of Steady and Transient Flow Boiling Critical Heat Flux for FeCrAl Accident Tolerant Fuel Cladding Alloy, Zircaloy, and Inconel}

Soon K. Lee ${ }^{1}$, Maolong Liu², Nicholas R. Brown ${ }^{3}$, Kurt A. Terrani ${ }^{4}$, Edward D. Blandford ${ }^{1}$, Heng Ban ${ }^{5}$, Colby

B.

Jensen ${ }^{6}$,

and

Youho

Lee $^{1,}$

* Corresponding Author: euo@unm.edu 
1: University of New Mexico, 1 University of New Mexico, Albuquerque, NM 87131

2: Shanghai Jiao Tong University, 1954 Huashan Rd, Shanghai, China 200000

3: Pennsylvania State University, Old Main, State College, PA 16802

4: Oak Ridge National Laboratory, P.O. Box 2008, Oak Ridge, TN 37831

5: University of Pittsburgh, 4200 Fifth Avenue, Pittsburgh, PA 15260

6: Idaho National Laboratory, 2525 Fremont Avenue, Idaho Falls, ID 83402

\section{ABSTRACT}

Steady and transient (with a heating rate of $685^{\circ} \mathrm{C} / \mathrm{s}$ ) internal-flow CHF (Critical Heat Flux) experiments were conducted under atmospheric pressure at a fixed inlet temperature $\left(40^{\circ} \mathrm{C}\right.$ or $\left.60^{\circ} \mathrm{C}\right)$ and mass flow $\left(300 \mathrm{~kg} / \mathrm{m}^{2} \mathrm{~s}\right)$ on Fe-13Cr-6Al alloy, Inconel 600 and Zircaloy-4 tube samples. Multiple experiments were repeated on the same specimen to investigate the effect of surface characteristic changes (i.e., roughness, wettability, and oxide scale morphology) on the occurrence of CHF. Despite notable changes of wettability, roughness, and oxide layer characteristics on samples that had already been subjected to CHF, measured flow CHF remained unchanged throughout repeated experiments for tested materials. This demonstrates that the surface effects on flow CHF are limited in the test conditions. In the steady-state flow boiling condition, Fe-13Cr-6Al alloy demonstrated a $22 \%$ and $14 \%$ increase in CHF compared to Zircaloy-4 and Inconel 600, respectively. Compared to the 2006 Groeneveld CHF lookup table, Fe-13Cr$6 \mathrm{Al}$ alloy gives a $13 \%$ increase in the tested flow boiling condition. Material properties are considered primarily responsible for the observed CHF differences among the tested materials. The surface thermal economy parameter $\left(\frac{\left(\rho c_{p}\right)^{3 / 2}}{\sqrt{k}}\right)$ is proposed as an explanation for the observed CHF differences; this parameter is related to material's ability to avoid an irreversible dry spot formation. The apparent disagreement of Zircaloy-4 CHF with both the look up table predictions and Inconel 600 shows the limitation of departure of nuclate boiling (DNB) evaluations that do not consider cladding materials. The transient $\mathrm{Fe}-13 \mathrm{Cr}-6 \mathrm{Al} \mathrm{CHF}$ is $39 \%$ and $23 \%$ higher than the lookup table prediction and the steady-state condition experimental result, respectively.

\section{KEYWORDS}

Accident Tolerant Fuel (ATF), Critical Heat Flux (CHF), FeCrAl, Reactivity Initiated Accident (RIA), Flow Boiling 


\section{INTRODUCTION}

FeCrAl alloy is considered as a potential alternative cladding material to the current zirconium-based alloy in Light Water Reactors (LWRs). Many studies have shown promise in using FeCrAl alloy as an LWR cladding material with enhanced ability to survive beyond design basis accident conditions. Desirable features of $\mathrm{FeCrAl}$ alloys include excellent tolerance for high temperature steam reactions [1], stable irradiation tolerance [2], acceptable fuel rupture and ballooning behavior [3,4], and accumulated experience of using metallic cladding material for LWRs. Accident Tolerant Fuel (ATF) research has been successful in gaining an improved understanding of the materials performance of $\mathrm{FeCrAl}$, there has been little evaluation of $\mathrm{FeCrAl}$ concepts from a thermal-hydraulics and reactor safety standpoint. In particular, understanding of Critical Heat Flux (CHF) for FeCrAl cladding alloys is necessary for detailed fuel design and reactor safety analysis. As a consequence, most ATF studies assume a similar fuel design, and allowable fuel pin power level using standard CHF correlations [5-12].

Additional transient CHF experiments are another data need to support reactor safety. In particular, rapid heating of nuclear fuel cladding during Reactivity Initiated Accidents (RIA) increases the fluid temperature gradient at the surface which results in an increased number of active nucleation sites $[13,14]$. This effect promotes heat transfer, and delays CHF, as demonstrated by several flow CHF experiments conducted under RIA conditions [15-18]. Nevertheless, prediction of fuel temperature during RIAs is still conducted using steady-state CHF models due to the lack of a satisfactory transient CHF model [19]. For mechanistic prediction of fuel failure during RIA for both the current Zircaloy clad fuels and advanced cladding fuels, further investigation of transient CHF phenomena is needed.

The Groeneveld CHF lookup table [20] is used for Zircaloy cladding in reactor thermal hydraulic codes (e.g. RELAP 5-3D and COBRA-TF), even though it which was developed experimentally using steel material. The impact of material type on CHF had been believed to be limited. However, in the past decade, studies have found potential impacts of the surface material on two-phase heat transfer, with highlights on surface effects $[21,22]$. Researchers predicted and experimentally confirmed an increase in pool boiling CHF with increase in wettability, surface roughness and porosity [21-24]. Investigations into surface effects were further augmented by nano-fluid enhancements for boiling heat transfer $[25,26]$. It is noteworthy that most surface-effect studies, if not all, were conducted under pool-boiling conditions [24]. Naturally, the exploration of material effects on two-phase heat transfer applies to ATF cladding 
materials. A limited number of studies have shown that different CHFs were observed in pool boiling environments for ATF cladding materials, including SiC and FeCrAl alloys [21,27].

Observation of material effects in pool boiling conditions provides evidence that CHF may vary for different cladding materials in flow boiling conditions. At this early stage of FeCrAl CHF research, it is logical to explore any change to $\mathrm{CHF}$ attendant upon the use of candidate ATF cladding (i.e. FeCrAl alloy) compared to Zircaloy and Inconel. Hence, this study investigates (1) experimental steady-state CHF measurements for Fe-13Cr-6Al alloy, Zircaloy-4, and Inconel 600 in identical flow conditions, (2) experimental transient CHF measurements under heating rates relevant to Reactivity Initiated Accidents (RIAs) for FeCrAl alloys, and (3) analysis of different CHFs for the tested materials using surface characteristics and material properties.

\section{EXPERIMENTAL SETUP and PROCEDURES}

\subsection{Flow Boiling Experiments}

Flow boiling CHF experiments were conducted for both steady-state and transient conditions relevant to RIA in the loop shown in Fig. 1(a). The flow boiling facility consists of the main circulation pump, orifice flow meters, pressure and temperature instrumentation, a heater, a test section, a tank separating steam and water, and a cooler. The loop is made of SS316 and deionized-water is used as a working fluid.

The length of a $50.8 \mathrm{~cm}$ (20 inch) test tubular specimen with the outer diameter of $9.525 \mathrm{~mm}$ is connected to the flow loop. Hence, experiments were conducted in the internal flow configuration. An entrance length of 10 inches ensured flow entering the heated length is fully-developed. As can be seen in Fig. 1(b), the actual heated length of the specimen is $5.08 \mathrm{~cm}(2 \mathrm{inch})$.

The whole test specimen is wrapped with an insulating material to curtail heat losses. The test section is heated with an increasing voltage supplied from a direct current power supply (Magna Power, TSA161200) through the two copper power terminals shown in Fig. 1(b). The power supply has $\sim 2 \mathrm{~ms}$ load transient response, which permits rapid shut down of the power applied to the test section once CHF conditions are reached. This avoids burn-out of the test specimen for multiple CHF experiments.

K-type thermocouples with a diameter of $0.05 \mathrm{~mm}(0.002 \mathrm{inch})$ were installed on the heated surface of tube to measure the surface temperature and to detect CHF. For steady-state experiments, a thermocouple 
was located at the top end of the heated length, approximately $\sim 5 \mathrm{~mm}$ from the upper power terminal. For transient experiments, a thermocouple was placed on the center of the heated length, $25.4 \mathrm{~mm}$ (1 inch) from the upper power terminal, for simplified transient CHF detection and calculation as actual location of CHF may not be at the end of the heated section due to transience. The acquisition rate of the temperature measurements is $50 \mathrm{~Hz}$ for both steady-state and transient condition experiments.

Even with carefully machined copper terminals, the junction between the copper terminals and tube material samples does not have perfect contact due to the roundness and roughness of the contacting surfaces. To reduce energy loss via contact resistance, nickel and silver compound is applied on the junction to maximize contact conductance. Due to the high thermal conductivity of copper terminals, transient heat loss from the heated section to the copper terminal causes variation in the axial location of CHF, which makes it difficult to identify the exact location of CHF along the specimen axis. To quantify transient CHF measurement uncertainty due to the thermocouple location, measurements were made with pulsed power using 5 thermocouples along axial locations at $5 \mathrm{~mm}$ intervals from the top end to the center of the test section, whose results indicated less than 3.3\% difference among the experimentally attained CHF values at each location. Throughout the experiments, loop was open to the atmosphere at the same water level in the tank ensuring a fixed atmospheric pressure of $84 \mathrm{kPa}$. The standard error of the 13 measured inlet temperature was less than $\pm 0.2^{\circ} \mathrm{C}$. The uncertainty of the flow velocity was less than $\pm 2 \%$.

(a)

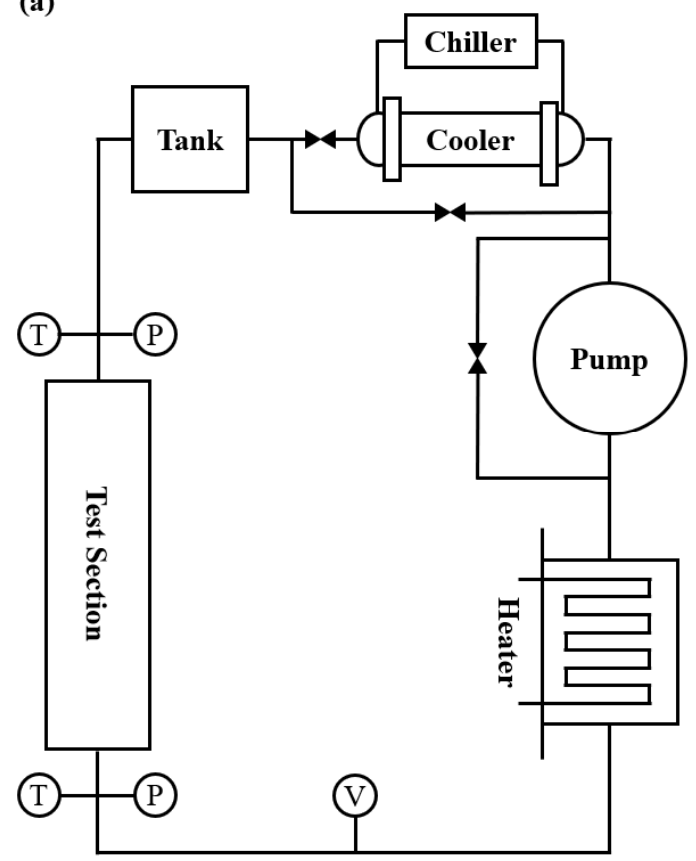

(b)

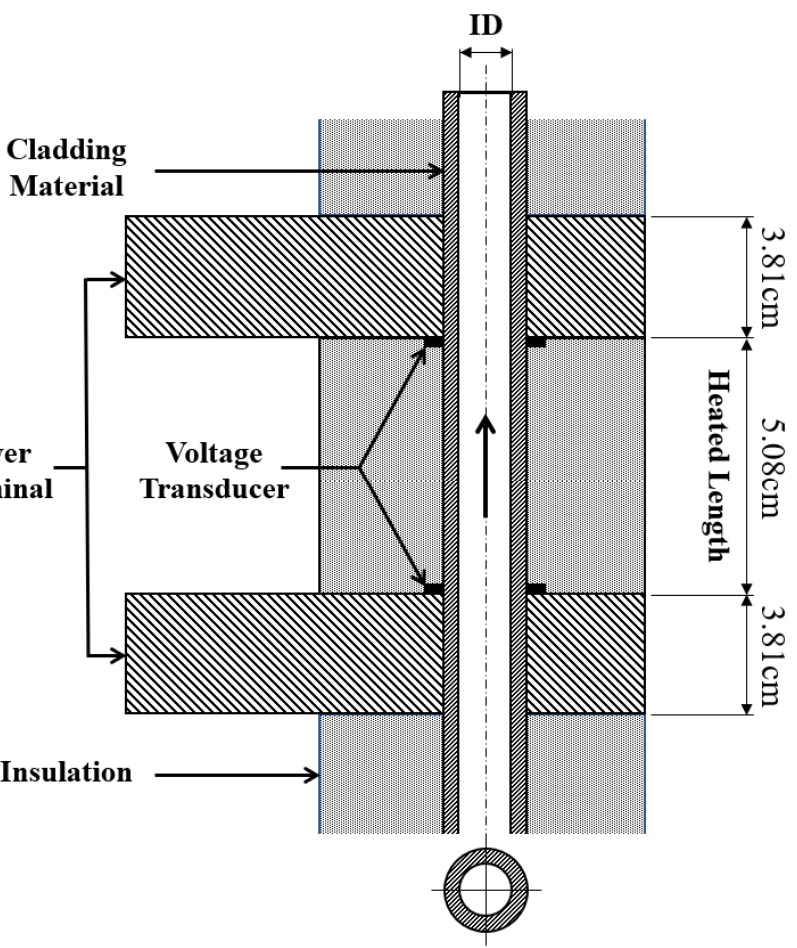


Figure 1. (a) Flow boiling loop schematic (b) cross-sectional view of the test section.

In the steady-state CHF study, flow boiling experiments were carried out under atmospheric pressure at a fixed inlet temperature $\left(40^{\circ} \mathrm{C}\right.$ or $\left.60^{\circ} \mathrm{C}\right)$ and mass flux $\left(300 \mathrm{~kg} \mathrm{~m}^{-2} \mathrm{~s}^{-1}\right)$ on Fe-13Cr-6Al alloy, Inconel 600 and Zircaloy-4 tube samples with internal flow (Table 1). Power was incremented at 30 second intervals until CHF occurred. The power supply was carefully controlled to shut down upon the occurrence of CHF to prevent damage to the sample. However, even with shut down of the power supply at CHF conditions, cladding burn-out eventually occurred after multiple runs. Experiments were repeated on the same sample until it reached burn out, and a number of samples was used to acquire 13 experimental data points for each cladding material. By doing repeated tests with the same sample, it allowed investigation of the effects of surface conditions on flow CHF while fixing all the other parameters.

Transient CHF experiments were conducted only on Fe-13Cr-6Al alloy specimens under the same pressure and mass flow. The working fluid's inlet equilibrium quality was set to that of the Fe-13Cr-6Al alloy's steady-state CHF point, assuming that thermodynamic quality at the time of departure from nucleate boiling (DNB) does not change significantly in transient conditions [15]. By doing this an impartial comparison can be made between steady-state and transient CHF under the same conditions: pressure, flow rate, and quality. The transient pulsed power was applied repeatedly on a given specimen for six runs. The pulsed power was shaped in a half sine curve with the pulse width of 1 second, which conforms to the average heating rate of $685^{\circ} \mathrm{C} / \mathrm{s}$. This pulse width was selected because it is similar to a subprompt ( $<\$ 1$ of reactivity) hot full power RIA in a LWR [28]. However, it is a much longer pulse than a superprompt ( $>\$ 1$ of reactivity) and/or hot zero power RIA [29]. The voltage, current, and outer wall temperatures were measured for post-experimental analysis.

Table 1. Flow boiling CHF test condition

\begin{tabular}{ccc}
\hline & Steady-state & Transient \\
\hline Mass flow $\left(\mathbf{k g} / \mathbf{m}^{\mathbf{2}} \mathbf{s}\right)$ & 300 & 300 \\
Pressure $(\mathbf{k P a})$ & 84 & 84 \\
Inlet quality & $-0.1 \&-0.064$ & -0.0068 \\
Input power & 0.01 voltage increment at & half sine shaped pulsed \\
& every 30 seconds & power peak: $5.8 \mathrm{MW} / \mathrm{m}^{2}$ \\
\hline
\end{tabular}




\subsection{Tested Materials}

Steady-state flow boiling CHFs were measured on Fe-13Cr-6Al alloy, Zircaloy-4 and Inconel 600 tubes with the geometry shown in Table 2. Transient flow boiling CHF was performed only on the FeCrAl alloy. Before each experiment, samples were thoroughly degreased and cleaned to eliminate outgassing from contamination using acetone, methanol, and deionized water.

$\mathrm{Fe}-13 \mathrm{Cr}-6 \mathrm{Al}$ is the first generation $\mathrm{FeCrAl}$ alloy that is from the same family as the alloy $\mathrm{C} 26 \mathrm{M}$ (Fe$12 \mathrm{Cr}-6 \mathrm{Al}-2 \mathrm{Mo}$ ), which is now being tested in the commercial reactor (Hatch-1) [30]. No notable heat transfer behavior differences between two alloys are expected as the composition is similar. The autoclave corrosion testing between two alloys shows no behavioral difference.

Table 2. Tested tube geometry for steady-state and transient experiments

\begin{tabular}{cccc}
\hline & Fe-13Cr-6AI & Zircaloy-4 & Inconel 600 \\
\hline Inner Diameter $(\mathbf{m m})$ & 8.763 & 8.255 & 8.509 \\
Outer Diameter $(\mathbf{m m})$ & 9.525 & 9.525 & 9.525 \\
Thickness $(\mathbf{m m})$ & 0.381 & 0.635 & 0.508 \\
Heated Length $(\mathbf{m m})$ & 50.8 & 50.8 & 50.8 \\
\hline
\end{tabular}

\section{RESULTS}

3.1. Steady-State CHF for Fe-13Cr-6Al alloy, Zircaloy, and Inconel 600

The CHF measurements were obtained by converting the applied power into heat flux at the instant of the over shoot of cladding temperature, as follows:

$$
q_{C H F}^{\prime \prime}=\frac{Q}{A_{\text {axial }}}=\frac{V I}{\pi D_{\text {inner }} L_{\text {heated }}}
$$


Where $\mathrm{Q}$ is applied power, $A_{\text {axial }}$ is test section inner surface, $V$ is applied voltage, $I$ is applied current, $D_{\text {inner }}$ is cladding inner diameter, and $L$ is heated length. Equilibrium quality $\left(\mathrm{X}_{\mathrm{e}}\right)$ at the location of CHF $\left(z_{C H F}\right)$ was evaluated as:

$$
X_{e}\left(z_{C H F}\right)=\frac{h_{m}^{+}\left(z_{C H F}\right)-h_{f}}{h_{f g}}
$$

where $h_{f}$ is the saturated liquid enthalpy, $h_{f g}$ is the enthalpy of vaporization, and $h_{m}^{+}$is the mixture enthalpy obtained by the following energy balance:

$$
h_{m}^{+}\left(z_{C H F}\right)=h_{i n}+\frac{1}{\dot{m}} \int_{0}^{z_{C H F}} q^{\prime} d z
$$

where $h_{i n}$ is the inlet enthalpy, $\dot{m}$ is the mass flow rate, and $q^{\prime}$ is the linear heat rate applied in the test section. Tests were conducted with the same inlet enthalpy $\left(h_{i n}\right)$ and mass flow rate $(\dot{m})$. Because CHF occurred at different applied heat fluxes for the tested materials, each CHF measurement resulted in variable equilibrium quality at CHF. For the same inlet enthalpy and mass flow a higher CHF results in a higher equilibrium quality. The experimental CHF results are compared to the 2006 Groeneveld lookup table at corresponding equilibrium quality. The lookup table predictions are corrected to the corresponding diameters of tested cladding materials for direct comparison [20].

Using the presented methodology, Fig. 2(a)-(c) show the experimental CHF values on each sample in the repeated experimental order. Each line in the figures represents the average CHF value and the lookup table prediction at same equilibrium quality. The Zircaloy-4 results in Fig. 2(b) have two different average $\mathrm{CHF}$ values as experiments were carried out with two inlet temperatures $\left(40^{\circ} \mathrm{C}\right.$ and $\left.60^{\circ} \mathrm{C}\right)$ on sample 1 and sample 2, respectively. The standard deviation of the CHF measurements is $212 \mathrm{~kW} / \mathrm{m}^{2}$, $157 \mathrm{~kW} / \mathrm{m}^{2}$, and $131 \mathrm{~kW} / \mathrm{m}^{2}$ for Fe-13Cr-6Al alloy, Zircaloy-4, and Inconel 600, respectively. The measured standard deviations for all cladding material are less than 10\% of its average CHF values. For each measured CHF points, lookup table predictions were compared at the corresponding equilibrium quality, which showed the standard deviation of $99 \mathrm{~kW} / \mathrm{m}^{2}, 76 \mathrm{~kW} / \mathrm{m}^{2}$, and $66 \mathrm{~kW} / \mathrm{m}^{2}$ for Fe-13Cr- $6 \mathrm{Al}$ alloy, Zircaloy-4, and Inconel 600, respectively. The measured standard deviations for all cladding material are less than 5\% of its average lookup table prediction CHF values. Under the reference flow conditions, Fe-13Cr-6Al alloy showed $22 \%$ and $14 \%$ increase in CHF compared to Zircaloy-4 and Inconel 600, respectively. No significant change in CHF was observed during repeated experiments as shown in Fig. 2. On the contrary, the nucleate boiling heat transfer coefficient fluctuated for repeated 
experiments. This may imply that the effect of surface characteristic change (i.e., oxide layer formation) has limited significance on CHF for the reference flow boiling condition. 
(a)

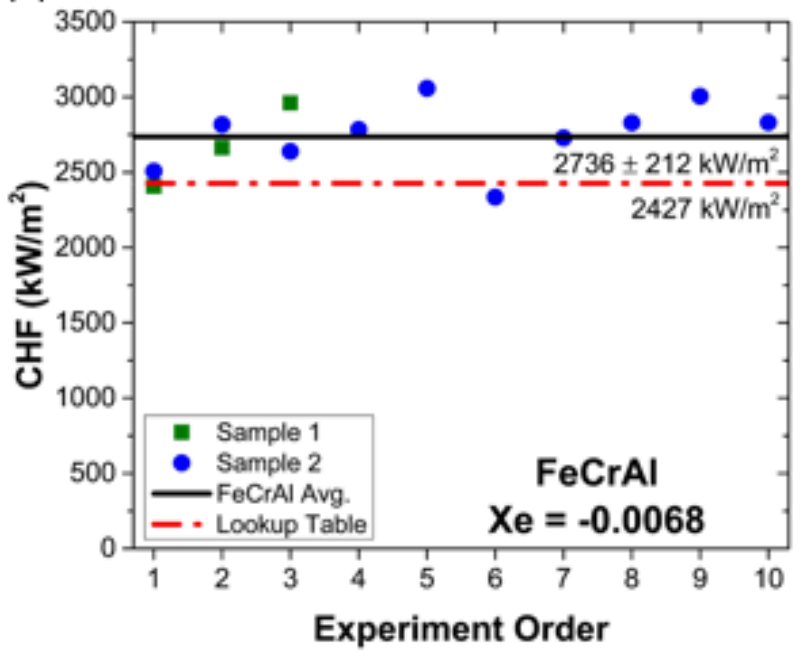

(b)

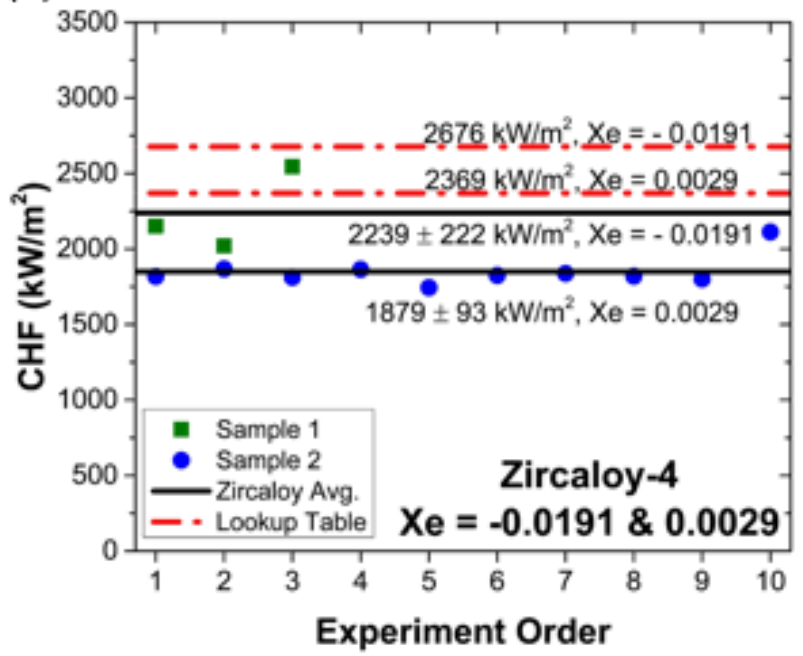

(c)

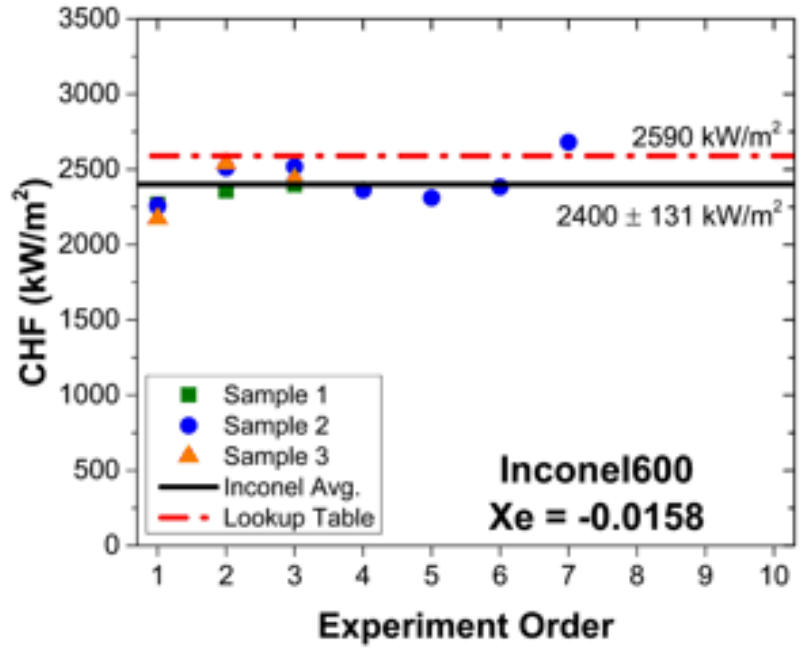


Figure 2. Repeated CHF measurements on the same test specimen (a) Fe-13Cr-6Al alloy, (b) Zircaloy-4, and (c) Inconel 600 tubes. The presented Xe and look-up table CHF are the average values. The Xe variations corresponding to the CHF measurements are $\pm 0.007, \pm 0.006$, and \pm 0.005 for FeCrAl, Zircaloy4, and Inconel 600, respectively. These variations entail the look-up table standard deviations of 99 $\mathrm{kW} / \mathrm{m}^{2} K, 76 \mathrm{~kW} / \mathrm{m}^{2} K$, and $66 \mathrm{~kW} / \mathrm{m}^{2} K$ for Fe-13Cr-6Al alloy, Zircaloy-4, and Inconel 600 , respectively.

In Fig. 3, the average experimental CHF data points of the three tube samples are compared to the lookup table predictions as a function of equilibrium quality. The Inconel $600 \mathrm{CHF}$ data exhibits good agreement with the corresponding lookup table predictions with a percent error of $-7 \%$. Zircaloy-4 experimental CHF data are $-16 \%$ and $-22 \%$ lower than lookup table prediction for two presented equilibrium qualities $\left(\mathrm{X}_{\mathrm{e}}=-0.0191\right.$ and 0.0029$)$, respectively. Fe-13Cr-6Al alloy experimental CHF data is $13 \%$ higher than the lookup table prediction, which may suggest an increased DNBR margin for the Fe-13Cr-6Al alloy clad fuel compared to the Zircaloy and Inconel 600 tubes.

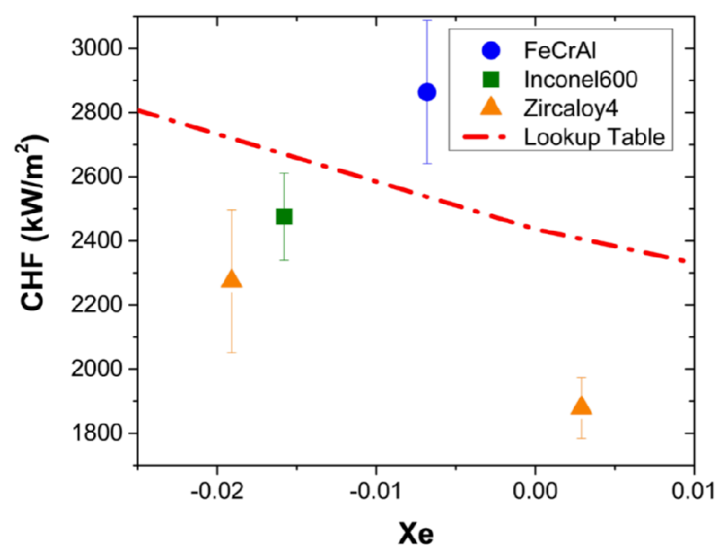

Figure 3. Average CHF data of Fe-13Cr-6Al Alloy, Zircaloy-4, and Inconel 600 tubes compared to the 2006 Groeneveld lookup table at corresponding Xe.

Boiling curves are obtained with the steady-state experimental data up to the CHF point on fresh tubes with fresh (CHF-unaffected) thermocouples under the reference flow condition (Fig. 4). The single phase boiling heat transfer coefficient $\left(\mathrm{h}_{\mathrm{SP}}\right)$ measurements are $21 \mathrm{~kW} / \mathrm{m}^{2} K, 16 \mathrm{~kW} / \mathrm{m}^{2} K, 22 \mathrm{~kW} / \mathrm{m}^{2} K$ for Fe13Cr-6Al alloy, Zircaloy-4, and Inconel 600 respectively. The apparent difference of $h_{S P}$, which is considered in the acceptable range, is mainly due to different flow diameter of the tube materials, and measurement uncertainties in the experiments. 
The nucleate boiling heat transfer coefficient, $\mathrm{h}_{\mathrm{NB}}$ measurements are $695 \mathrm{~kW} / \mathrm{m}^{2} K, 133 \mathrm{~kW} / \mathrm{m}^{2} K$, and $344 \mathrm{~kW} / \mathrm{m}^{2} \mathrm{~K}$ for Fe-13Cr-6Al alloy, Zircaloy-4, and Inconel 600 respectively. Material with a higher heat transfer coefficient induces higher CHF at a lower wall superheat, as shown in Fig. 4.

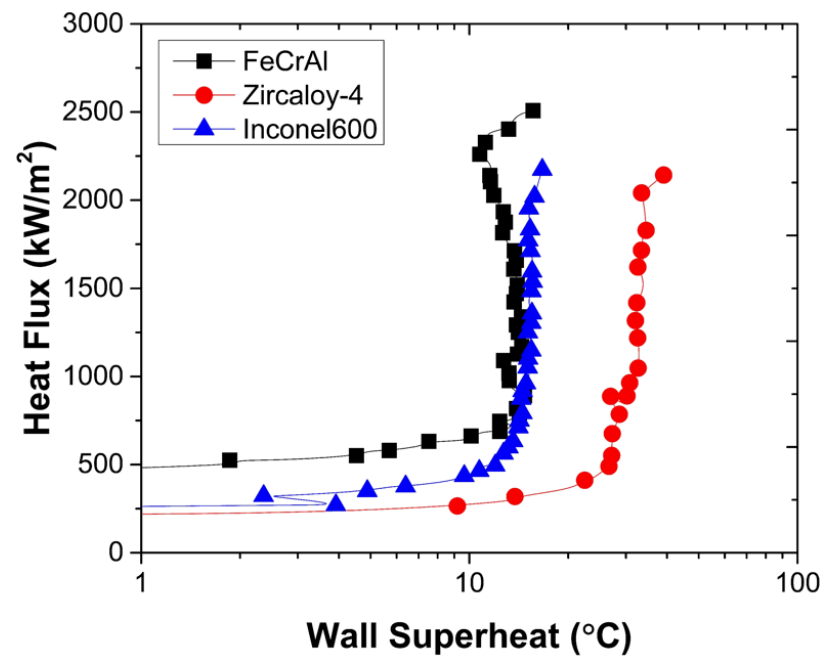

Figure 4. Boiling curves for Fe-13Cr-6Al alloy, Zircaloy-4, and Inconel 600 tubes at the identical flow condition (Fe-13Cr-6Al alloy sample 2 order 1, Zircaloy-4 sample 1 order 1, Inconel 600 sample 3 order 1)

\subsection{Transient $\mathrm{CHF}$ for $\mathrm{Fe}-13 \mathrm{Cr}-6 \mathrm{Al}$ alloy}

The transient CHF value, $q_{C H F, R I A}^{\prime \prime}$ in the test section is obtained at the instant of rapid temperature overshoot, using the transient energy balance as follows:

$$
q_{C H F, R I A}^{\prime \prime}=\left(Q-M c_{p} \frac{d T}{d t}\right) / A_{\text {inner }}
$$

Where $Q$ is the applied heat generation rate in the test section, $\mathrm{M}$ is mass of the heated test section, $c_{p}$ is the specific heat, $\mathrm{T}$ is the measured temperature of the test section, and $A_{\text {inner }}$ is the internal surface area of the test specimen, as shown in Fig. 5(a). The specific heat capacity of Fe-13Cr-6Al alloy changes drastically with respect to the cladding temperature. The specific heat of the $\mathrm{FeCrAl}$ alloy model is used to obtain values matching the cladding temperature [31]. 
(a)

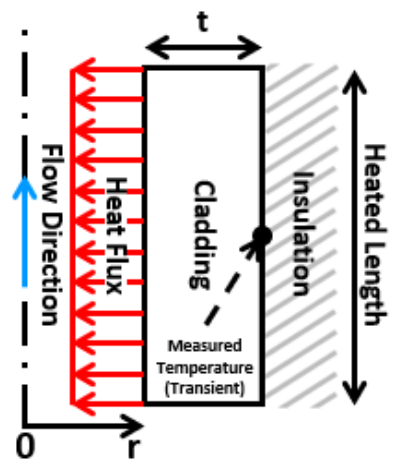

(b)

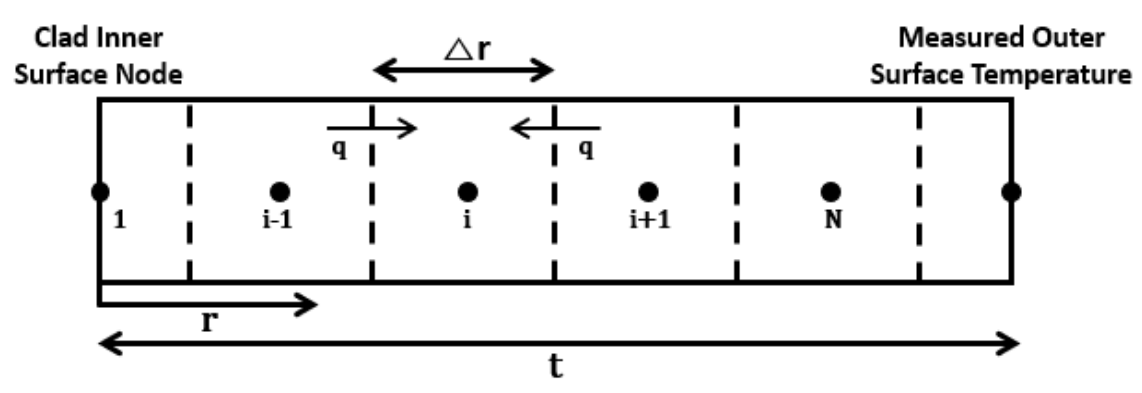

Figure 5. (a) Energy balance schematic (b) cladding nodalization for cladding inner wall analysis

Cladding inner surface temperature is obtained by solving 1-D transient radial conduction equation (Eq.5) with the implicit finite difference method (FDM).

$$
\frac{1}{r} \frac{d}{d r}\left(k r \frac{\partial T}{\partial r}\right)+\dot{q}=\rho c_{p} \frac{\partial T}{d t}
$$

The Neumann boundary condition is adopted employing measured temperature on the cladding outer surface and calculated transient heat flux $\left(q_{R I A}^{\prime \prime}\right.$ in Eq.(4)) on the FDM. The following governing equations (Eq.(6)-(8)) for discretized nodes in the cladding domain shown in Fig. 5(b) were derived from the energy balance equation taking account of radial heat conduct, heat generation, and time rate of change of the heat energy of each nodes. Eq.(6)-(8) were solved by taking the inverse of the matrix operator $\mathrm{A}^{-1}$ in $\mathrm{A} \overrightarrow{\mathrm{x}}=b$.

Cladding inner surface node, $i=1$

$$
-q_{R I A}^{\prime \prime} A_{1}+\frac{k}{\Delta r}\left(T_{2}^{P+1}-T_{1}^{P+1}\right) A_{2}+Q^{P+1} \frac{V_{1}}{V_{t o t}}=\rho c_{p} V_{1} \frac{T_{1}^{P+1}-T_{1}^{P}}{\Delta t}
$$

Cladding inner node, $i$

$$
\frac{k A_{i-1}}{\Delta r}\left(T_{i-1}^{P+1}-T_{i}^{P+1}\right)+\frac{k A_{i+1}}{\Delta r}\left(T_{i+1}^{P+1}-T_{i}^{P+1}\right)+Q^{P+1} \frac{V_{i}}{V_{t o t}}=\rho c_{p} V_{i} \frac{T_{i}^{P+1}-T_{i}^{P}}{\Delta t}
$$

Cladding outer node, $i=N$ 


$$
\frac{k A_{N-1}}{\Delta r}\left(T_{N-1}^{P+1}-T_{N}^{P+1}\right)+\frac{k A_{N}}{\Delta r}\left(T_{M e a s u r e d}^{P+1}-T_{N}^{P+1}\right)+Q^{P+1} \frac{V_{N}}{V_{t o t}}=\rho c_{p} V_{N} \frac{T_{N}^{P+1}-T_{N}^{P}}{\Delta t}
$$

A temperature distribution of the cladding from inner wall to outer wall is shown in Fig. 6. At the cladding outer surface, the temperature gradient is zero, matching the insulation condition though not explicitly prescribed in the applied boundary conditions. The wall superheat at the transient condition $\mathrm{CHF}$ (or DNB) is approximately $30^{\circ} \mathrm{C}$ higher compared to the wall superheat at the steady-state $\mathrm{CHF}$ under the reference test condition.

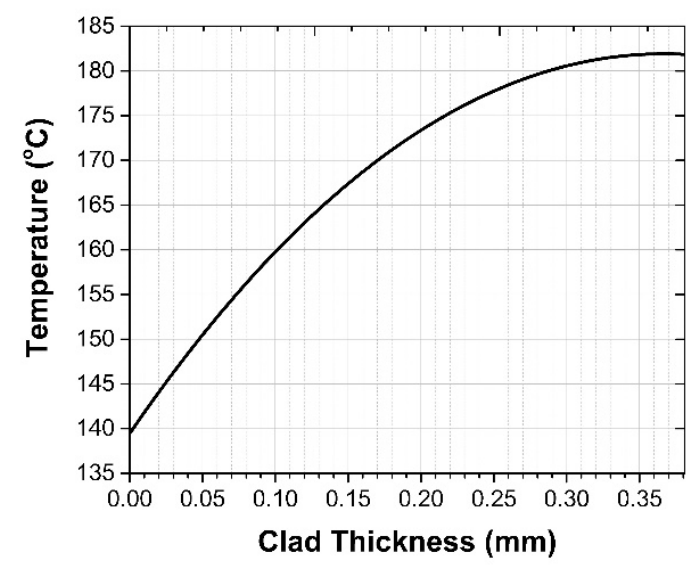

Figure 6. Temperature distribution along radial axis of Fe-13Cr-6Al alloy at DNB (transient experiment order 1, pulsed power: 1 second width and peak at 8088 Watts)

Experimental measurements of the RIA-like experiments with the applied power are shown in Fig.7(a). Evaluation of cladding inner wall temperature utilizing the FDM enables identification of the DNB and rewetting point. In Fig. 7(b), a sharp increase in the temperature compared to the previous time step is observed at 1.36 seconds. This point corresponds to the occurrence of CHF, representing the transition from nucleate to film boiling. As the cladding temperature decreases after CHF without applied power, a point is reached where the vapor film is no longer sustained and the condition changes to transition boiling. This moment represents the rewetting point; in Fig. 7(c), sudden temperature drop in the cladding inner wall temperature with increasing heat flux is reported to be the rewetting point. 
(a)

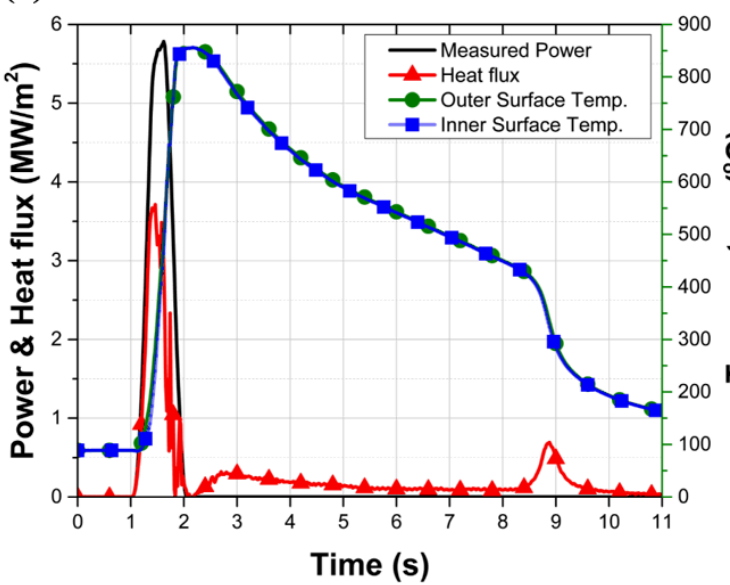

(b)

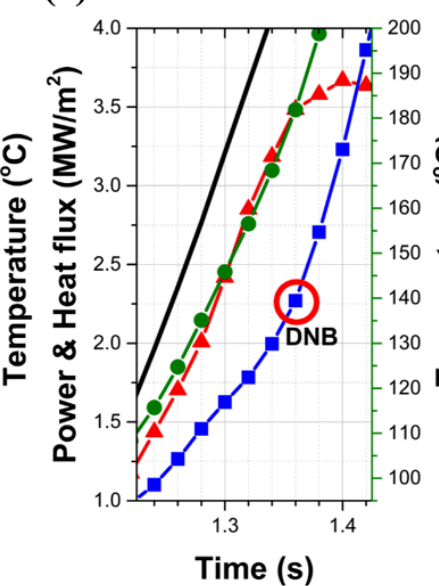

(c)

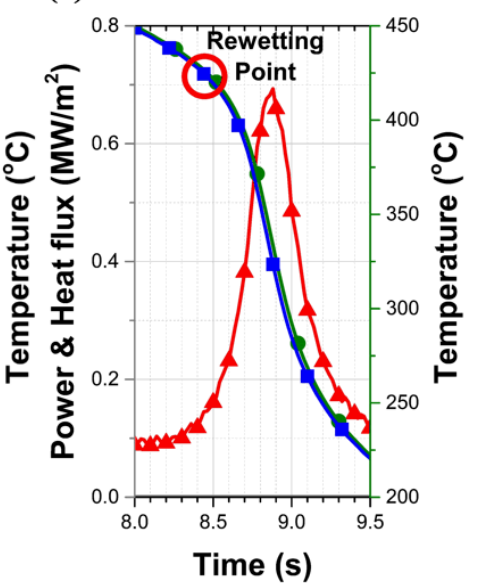

Figure 7. (a) Measured power and cladding outer wall temperature and calculated heat flux and cladding inner wall temperature for a RIA experiment (transient experiment order 1, pulsed power: 1second width and peak at 8088 Watts) with the Fe-13Cr-6Al alloy, (b) CHF point determination, and (c) Rewetting point determination

Similar to the steady-state experiments, identical experiments were repeated on the same sample specimen for the RIA testing to explore potential change in CHF and rewetting points after alteration of material surface conditions (i.e., oxidation) due to CHF. As shown in Fig. 8(a) and (b), CHF and rewetting points stay unchanged during repeated tests, implying limited surface effects on transient CHF and rewetting. Compared to the steady-state $\mathrm{CHF}$, the transient CHF testing conducted with pulsed power shows the notable increase in CHF for the Fe-13Cr-6Al alloy. As indicated in Fig. 8(a), at the same reference flow condition, the transient $\mathrm{CHF}$ is found to be $39 \%$ and $23 \%$ higher than the lookup table prediction and the steady-state condition experimental result, respectively. Experimental CHF and rewetting points show repeatability with standard deviation of $109 \mathrm{~kW} / \mathrm{m}^{2}$ and $15 \mathrm{~kW} / \mathrm{m}^{2}$. 
(a)
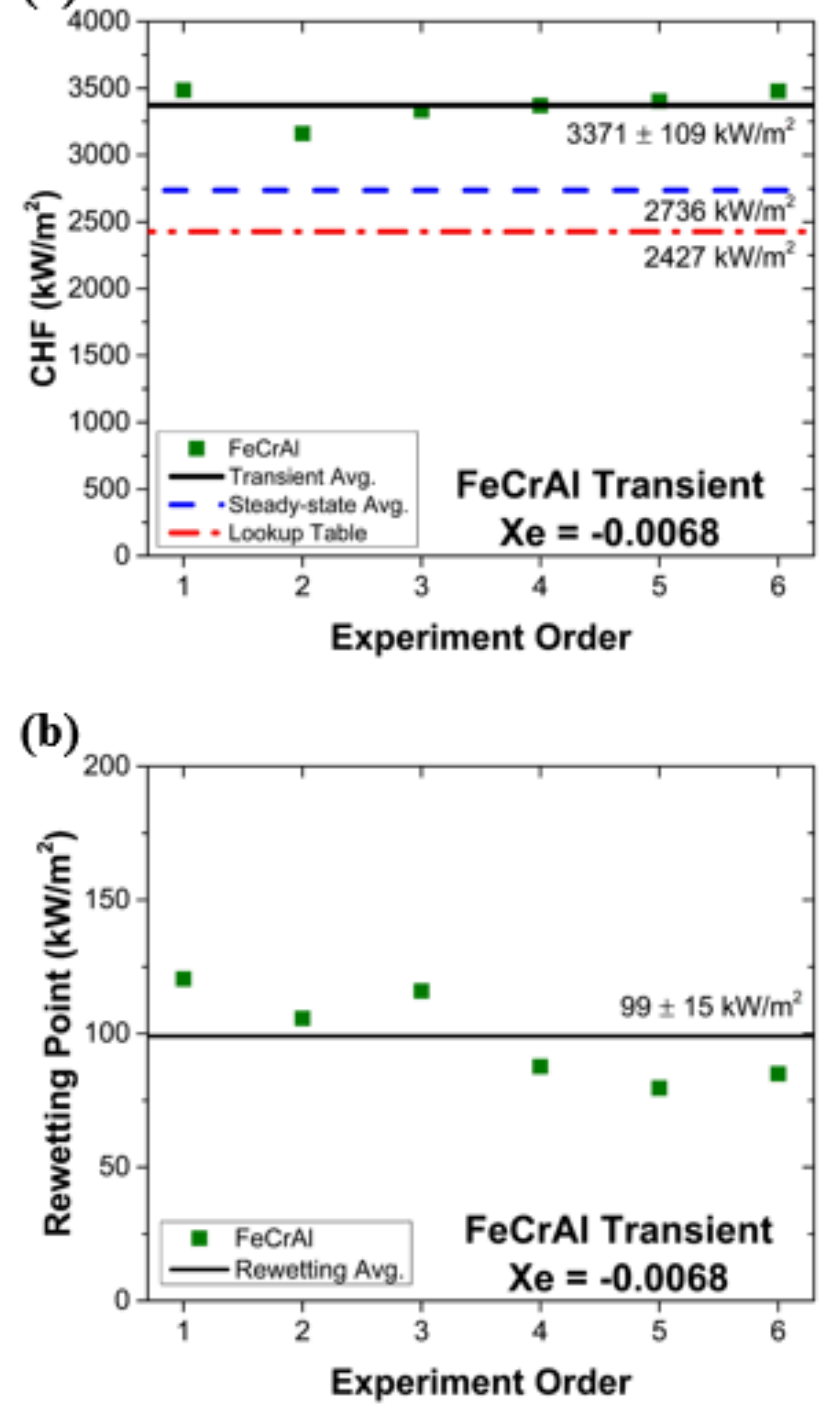

Figure 8. Experimental transient (a) CHF data compared to the steady-state CHF data and the lookup table prediction (b) rewetting points of Fe-13Cr-6Al alloy.

\section{DISCUSSION}

\subsection{Implications of Roughness on Flow CHF}

Surface roughness has been known to have effect on CHF due to its association with micro-cavities that trigger bubble nucleation. However recent studies claim roughness has minimal effect on CHF [15, 21]. In this study, as-received and post-CHF surface roughness was measured to explore its implication on CHF. 
Measurements were performed using the stylus profilometer (Dektak 8). Five scans were conducted on each material with 2000-micron scan length measuring arithmetical mean roughness $R_{a}$. Measurement results indicate roughness increases on post-CHF specimens compared to as-received specimen. Formation of oxide layers is considered responsible for the change. The roughness of steady-state experiment surfaces is $4.53 \mu \mathrm{m}, 1.61 \mu \mathrm{m}$, and $3.13 \mu \mathrm{m}$ on Fe-13Cr-6Al alloy, Zircaloy-4, and Inconel 600 respectively, showing minimal roughness change in Inconel 600. Transient CHF tested surfaces have less increase in roughness compared to steady-state CHF tested surface.

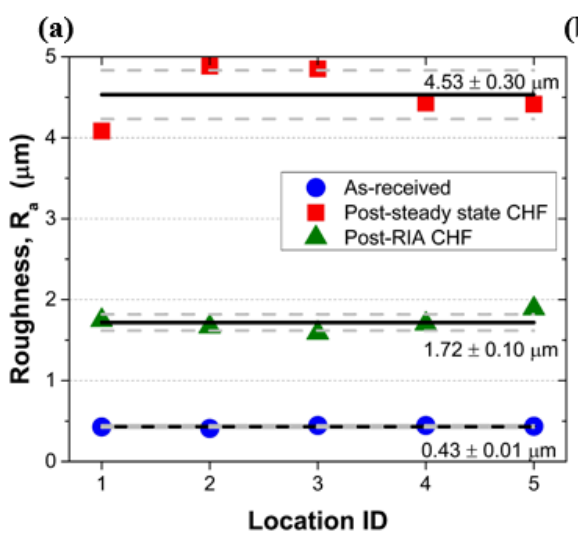

(b)

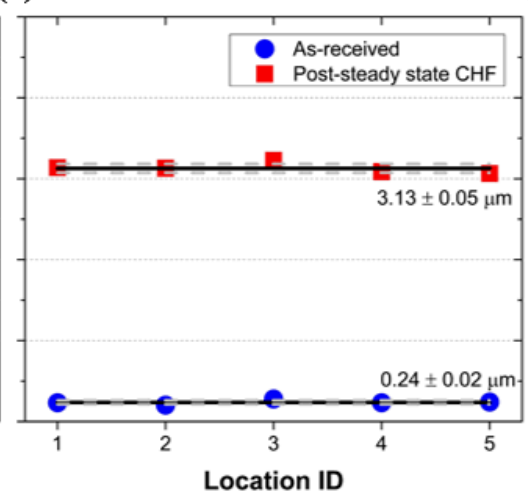

(c)

Figure 9. Surface roughness comparison of as-received, steady-state CHF and transient CHF tested surfaces for (a) Fe-13Cr-6Al alloy (10 steady state CHF and 6 RIA CHF experiments), (b) Zircaloy-4 (10 steady state CHF experiments), and (c) Inconel 600 (7 steady state CHF experiments), the dashed lines indicate standard deviations

Despite the notable change of surface roughness, CHF stayed unchanged in the repeating tests. This implies limited significance of roughness for CHF in the tested flow condition.

\subsection{Implications of the Wettability on Flow CHF}

Increased surface wettability is known to enhance CHF in pool boiling [21]. In this study, wettability of as-received and post-CHF were quantified by measuring contact angles. The contact angles were measured following the procedure described by American Society of Testing Materials (ASTM) [32]. For each material, contact angles were measured on as-received surfaces and post-CHF surfaces. Sample number 2 of each material shown in Fig. 2(a-c) was used for the measurement. Additionally, measurements of post RIA-CHF surface wettability were conducted for Fe-13Cr-6Al alloy. For each 
surface, five measurements were performed at the room temperature with the minimal sized deionized water droplet of $5 \mu \mathrm{L}$ to minimize curvature effects from of the claddings (Fig.10).

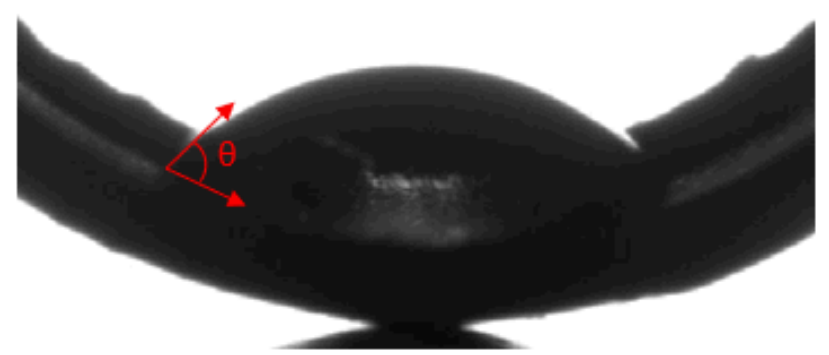

Figure 10. Contact angle measurement of Inconel 600 as-received inner surface.

Measurements indicate increased wettability on tested (post-CHF) surfaces compared to the as-received surfaces as shown in Fig. 11. Formation of an oxide layer is considered responsible for the observed wettability increase. Gradual oxidation layer growth on the inner surface (the coolant side) for each material is expected as the boiling experiments are repeated on a given sample. Even with immediate shut down of the power supply when it meets the CHF condition, the cladding temperature rises to sufficient temperatures for the oxide layer to grow. Despite the wettability change, no appreciable change in CHF was observed during repeated experiments for all tested specimens. This result clearly indicates that the effect of surface wettability in the contact angle range of $50^{\circ} \sim 80^{\circ}$ has limited influence on flow boiling CHF. That is, unless materials with extreme wettability are used (i.e., extreme hydrophobic or hydrophilic surfaces), influence of wettability on flow CHF is likely limited for most engineering materials.

(a)

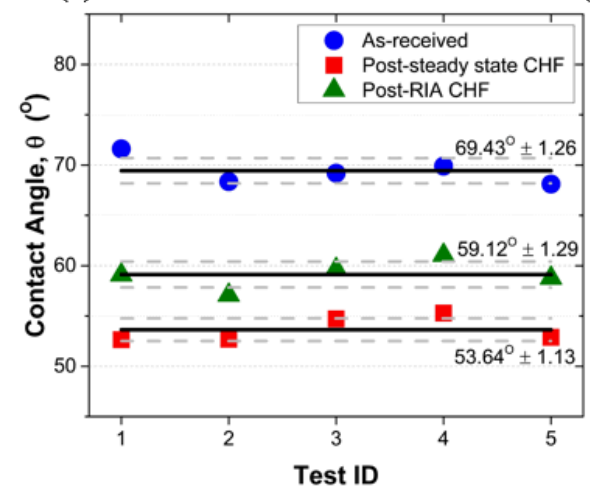

(b)

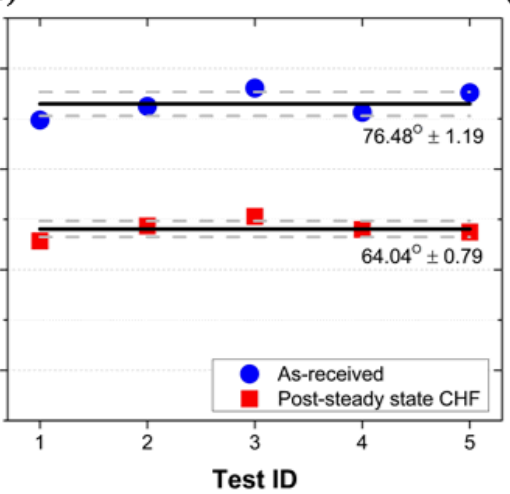

(c)

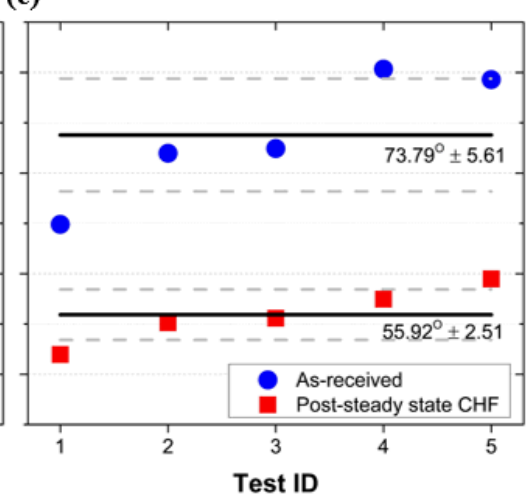

Figure 11. Contact angle comparison of as-received, steady-state CHF and transient CHF tested surfaces for (a) Fe-13Cr-6Al alloy (10 steady state CHF and 6 RIA CHF experiments), (b) Zircaloy-4 (10 steady state CHF experiments), and (c) Inconel 600 (7 steady state CHF experiments), the dashed lines indicate standard deviations 
Scanning electron microscopy (SEM) images were taken to investigate morphology differences and the evolution of measured surfaces and are shown in Figure 12-14. The SEM observations of Zircaloy-4 and Inconel 600 surfaces after steady-state CHF condition show a homogeneous distribution of oxidation as shown in Fig. 13(b) and Fig. 14(b). The Fe-13Cr-6Al alloy surfaces show a densely formed layer and dislocations of the oxide layer (see Fig. 12(b)). Compared to the "post-steady-state CHF" surface, the "post-transient CHF" surface shows localized oxidation and cracks (see Fig. 12(c)) in the surface. The post-steady-state CHF surface was exposed to the high temperature working fluid longer than the sample in transient CHF conditions. Therefore, less oxidation occurs in the transient CHF condition. This conclusion can also be derived from the wettability and roughness measurements. Consequently, though oxide layer formation increased wettability as the contact angles decreased by $\sim 12^{\circ}$ to $18^{\circ}$, the experimental results did not exhibit a significant increase in CHF.
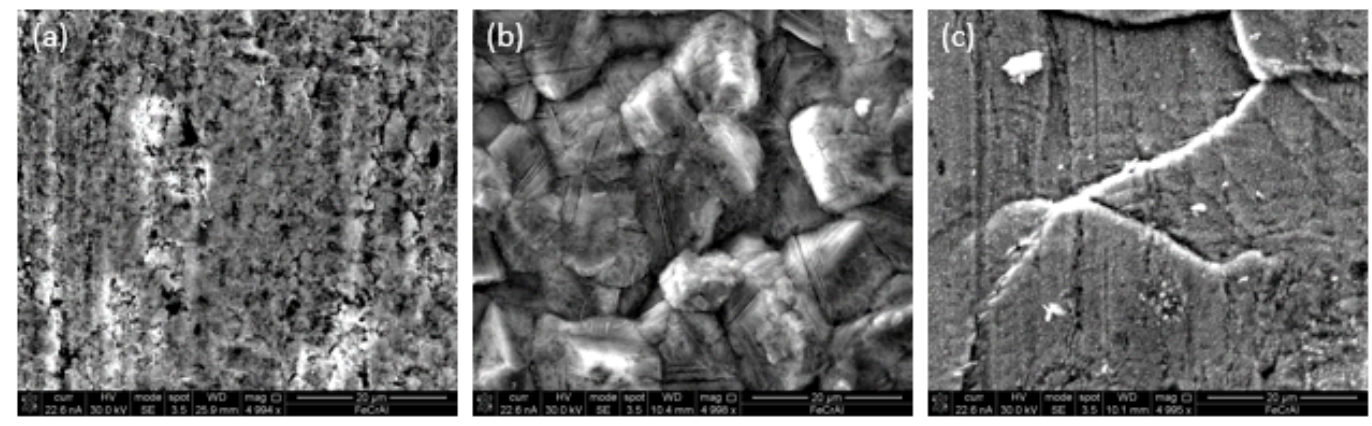

Figure 12. SEM micrograph of Fe-13Cr-6Al alloys inner surface in (a) as-received, (b) after 10 steadystate CHF measurements, and (c) after 6 transient CHF measurements.
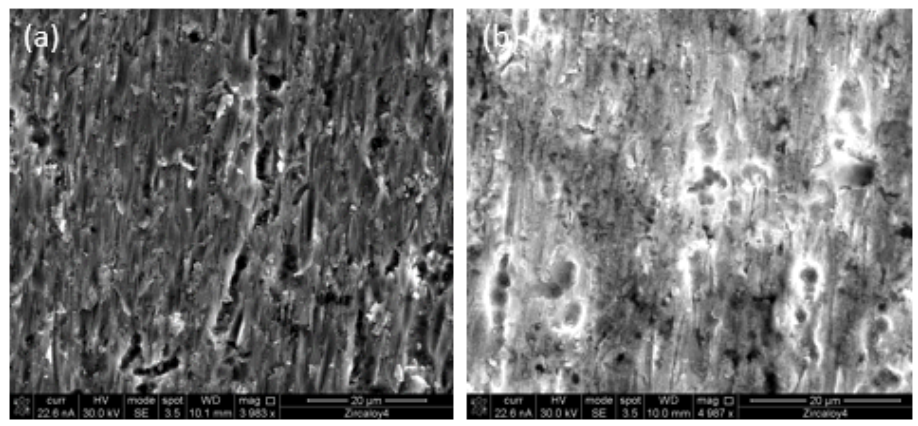

Figure 13. SEM micrograph of Zircaloy-4 inner surface in (a) as-received, (b) after 10 steady-state CHF measurements. 

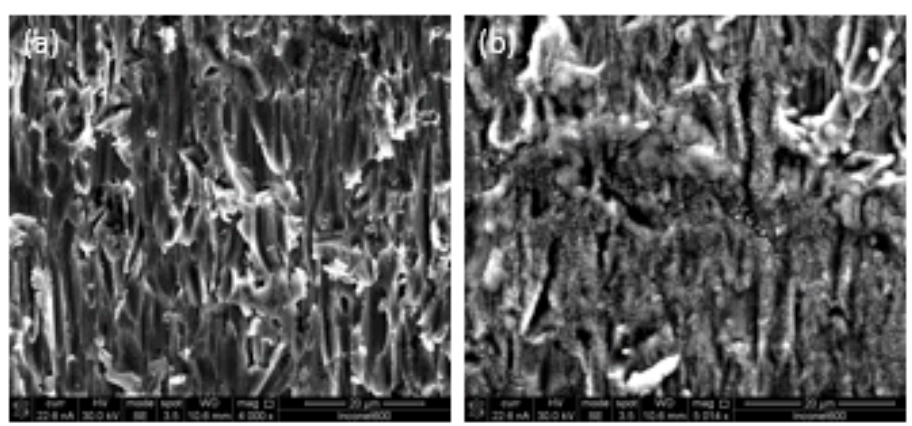

Figure 14. SEM micrograph of Inconel 600 inner surface in (a) as-received, (b) after 7 steady-state CHF measurements

\subsection{Implications of Thermal Properties on CHF}

The observed insignificance of surface characteristics on flow CHF may be an effect of differing thermal properties among the tested materials (Fe-13Cr-6Al alloy, zircaloy-4, and Inconel 600).

Thermal effusivity, $e=\sqrt{k \rho c_{p}}$, represents a material's ability to thermally interact with surroundings. A material with a higher thermal effusivity (i.e., a higher thermal conductivity $(k)$, or a high thermal capacity $\left.\left(\rho c_{p}\right)\right)$ has higher significance in exchanging heat with its surrounding in transient conduction. The implication of thermal effusivity for boiling can be explained by the analytical solution for the instantaneous $(\mathrm{t}=0)$ interface temperature $\left(\mathrm{T}_{\text {interface }}\right)$ upon the contact of two infinite media (material 1 and material 2), given by Eq. (9) [33].

$$
\mathrm{T}_{\text {interface }}=\frac{\left(\sqrt{k \rho c_{p}}\right)_{1} T_{1}+\left(\sqrt{k \rho c_{p}}\right)_{2} T_{2}}{\left(\sqrt{k \rho c_{p}}\right)_{1}+\left(\sqrt{k \rho c_{p}}\right)_{2}}
$$

As can be inferred by Eq. (9), the interface temperature increases for solids with a higher thermal effusivity upon the quenching of cold water during the boiling process. That is, thermal effusivity determines the interface temperature impacting thermal gradient of liquid microlayer on the heated surface, which regulates the number of active nucleation sites. The higher effusivity increases the number of active nucleation sites, thereby promoting effective heat dissipation to the contacting fluid. This effect may help prevent a local hot spot from becoming an irreversible dry spot and increase CHF as a consequence [34]. 
The effect of thermal activity $\left(\delta \sqrt{k \rho c_{p}}\right)$ can be understood as an extension of the thermal effusivity discussion. The boiling process, including bubble growth, departure, and subsequent water quenching, occurs over a finite time period, and involves a finite length scale for the mass, energy, and momentum transfer. Unless sufficiently thick, the boiling processes is impacted by the finite size of the material. The semi-infinite medium condition of Eq. 8 is quickly violated with thin heater wall thickness. Thus, material wall thickness $(\delta)$ is introduced as a factor with thermal effusivity, $\delta \sqrt{k \rho c_{p}}$, to account for finite heater thickness in evaluating material thermal interaction with the coolant. Several studies investigated heater thickness effects on CHF in pool boiling [34-37]. As anticipated, CHF increases asymptotically with increasing thickness in pool boiling, until reaching a limiting value beyond which the increasing heater size does not play a role [35-37].

In this study, no clear relation between CHF and thermal effusivity (Fig. 15(a)), and CHF and thermal activity (Fig. 15(b)) was found. This could be partly due to the relatively small range of thermal effusivities and thermal activities of the tested materials.

Another thermal parameter of importance is thermal diffusivity $\left(\alpha=\frac{k}{\rho c_{p}}\right)$. Thermal diffusivity determines the rate of temperature change during transient heat transfer. In the boiling process, higher thermal diffusivity promotes heat flow into the cold spot, thereby contributing to fast recovery of the surface temperature. Hence, $\mathrm{CHF}$ is considered inversely proportional to thermal diffusivity. This trend is observed for the tested materials to a certain degree, as can be seen in Fig. 15(c). Yet, given the wide range of the thermal diffusivities covered by the tested materials $(\sim 4$ times difference between FeCrAl and Zircaloy-4), the CHF sensitivity appears limited. 
(a)

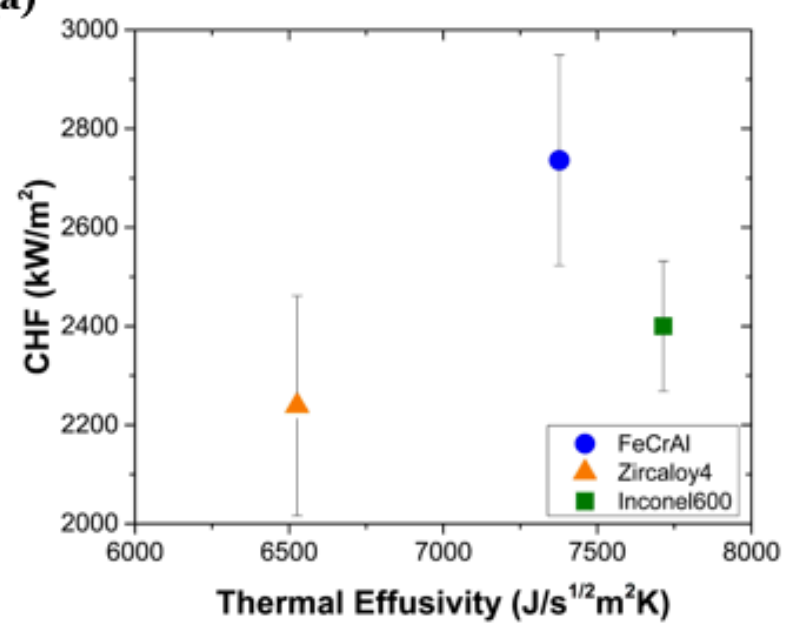

(b)

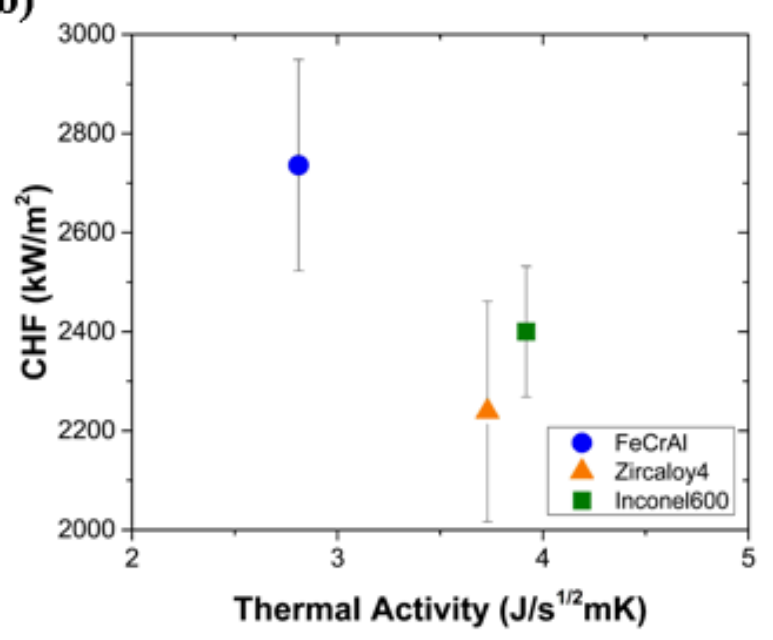

(c)

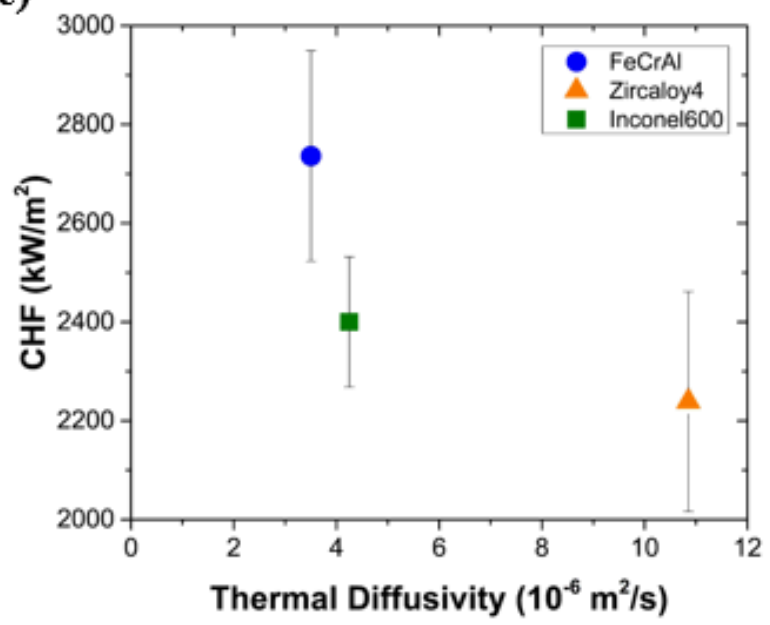

Figure 15. CHF as a function of thermal properties: (a)Thermal Effusivity, (b)Thermal Activity, and (c)Thermal Diffusivity 
As discussed, thermal effusivity (beyond the threshold thickness) primarily governs surface heat dissipation to liquid. Hence, $\mathrm{CHF}$ is generally proportional to it $\left(\mathrm{q}_{C H F}^{\prime \prime} \sim \sqrt{k \rho c_{p}}\right)$. On the contrary, thermal diffusivity governs solid heat conduction rate to the local cold spot, hence $\mathrm{q}_{C H F}^{\prime \prime} \sim \frac{1}{k / \rho c_{p}}$. These two competing effects illustrated in Fig. 16 should be simultaneously considered.

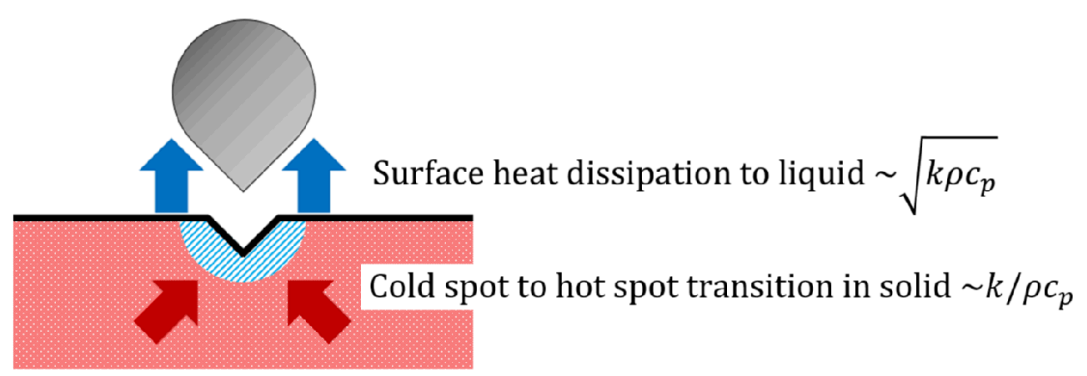

Figure 16. Illustration of two competing heat components governing the temperature change rate of a boiling surface

Hence, we propose the new 'Surface Thermal Economy' parameter $\frac{\left(\rho c_{p}\right)^{3 / 2}}{\sqrt{k}}$, by taking the ratio of thermal effusivity to thermal diffusivity, as follows

$\mathrm{q}_{C H F}^{\prime \prime} \sim \frac{\text { Heat dissipation rate to liquid }}{\text { Solid Heat conduction rate to cold spot }} \sim \frac{\text { Thermal Ef fusivity }}{\text { Thermal Diffusivity }}=\frac{\sqrt{k \rho c_{p}}}{\frac{k}{\rho c_{p}}}=\frac{\left(\rho c_{p}\right)^{3 / 2}}{\sqrt{k}}$

The surface thermal economy parameter $\frac{\left(\rho c_{p}\right)^{3 / 2}}{\sqrt{k}}$ represents the ratio of the ability to dissipate heat to the contacting liquid to the ability to draw heat to the cold spot via solid conduction. As evident in its definition, it is related to material's ability to avoid an irreversible dry spot formation. As can be noted in Fig. 17, it gives a satisfactory explanation for the obseverd CHF differences for the tested materials with a clear positive relation. 


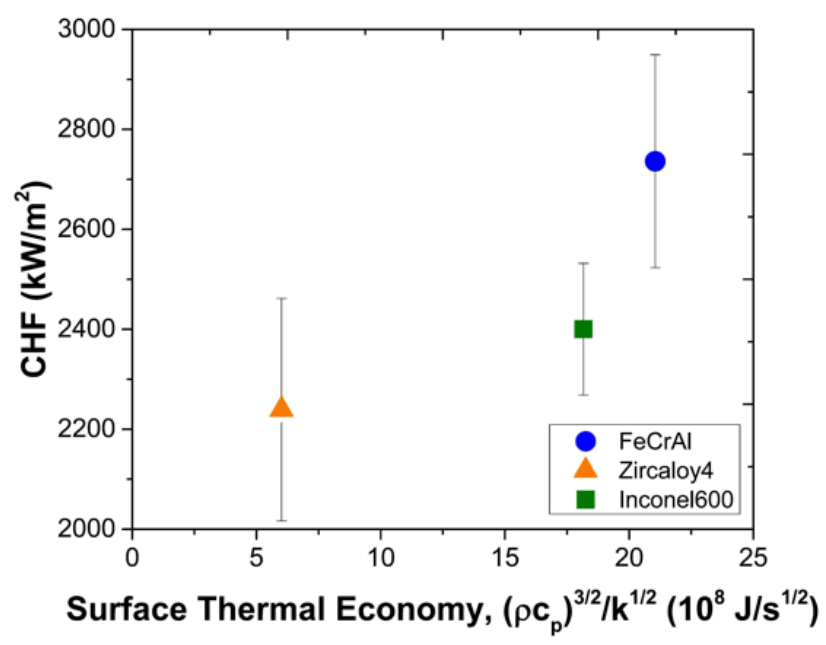

Figure 17. Relationship between measured CHF and surface thermal economy parameter $\frac{\left(\rho c_{p}\right)^{3 / 2}}{\sqrt{k}}$

Contrary to the surface-insensitive CHF analyses, the material thermal properties provide a more plausible explanation for the observed CHF differences. Consequently, it can be tentatively concluded that thermal properties of the materials are primarily responsible for the CHF differences between the tested materials in the tested flow boiling condition.

\subsection{Boiling Curve Construction for FeCrAl Alloy}

In this section, detailed prototypical procedures for constructing steady and transient boiling curves are discussed for a potential implementation in reactor analysis codes. By finding Onset of Nucleate Boiling (ONB) and CHF, one can construct steady- boiling curve up to the CHF point with interpolations. Each measurable point comprising the steady-steady boiling curve (1) and (2) in Fig.18(a)) can be found as follows:

(1) Steady-state ONB: ONB was measured when the slope of the boiling curve sharply increases.

(2) Steady-state CHF: CHF can be measured when cladding temperature overshoots.

Prototypical procedures for the transient boiling curve construction using experimentally measureable points (3) - (7) in Fig.18(b)) are demonstrated as follows: 
(3) Transient CHF: transient CHF can be measured when cladding temperature increase rate overshoots during transience.

(4) Film boiling heat transfer coefficient $\left(h_{\text {film }}\right)$ : $h_{\text {film }}$ is obtained from the heat flux change rate with respect to the cladding surface change $\left(\frac{d q^{\prime \prime}}{d T_{S}}=h\right)$ during the film boiling phase. For the conducted experiment with Fe-13Cr-6Al, $\mathrm{h}_{\text {film }}$ is found to be $\approx 291 \mathrm{~W} / \mathrm{m}^{2} \mathrm{~K}$ which is in a good agreement with the Bishop-Sandberg-Tong[38] correlation within 5.5\% error. As can be noted, in Fig. 18 (a), it serves as the gradient in the film boiling curve which can be connected to point (5).

(5) Rewetting point: rewetting point is characterized with an onset of sharp surface temperature decrease after the film boiling regime. The surface temperature at this point corresponds to the minimum film boiling temperature $\left(\mathrm{T}_{\mathrm{MFB}}\right)$.

(6) Maximum attainable heat flux with liquid quenching: this point is characterized with the peak heat flux attained by the recovery of heat transfer rate upon the transition of film boiling to nucleate boiling. It can be noted that this point is closely located on the fictitious straight line connecting the point (3) and (5).

(7) Onset of single phase convection: this point is characterized with a further decrease in the cladding heat flux change with respect to cladding temperature change $\left(\frac{d q^{\prime \prime}}{d T_{s}}=h\right)$ after the point (6). This point, however, is not always clearly detectable due to the low temperature and heat flux.

The transient ONB point would have completed the transient boiling curve. However, its precise measurement was not possible in the presented experimental setup due to the limited thermocouple response time. Heat transfer rate before CHF is considered to have limited significance in the cladding temperature prediction during the entire RIA transience due to the rapid heating of the cladding caused by applied power. Hence, the part of the transient boiling curve prior to CHF can be acquired by using steady-state correlations based on assumptions found in [6]. 
(a)

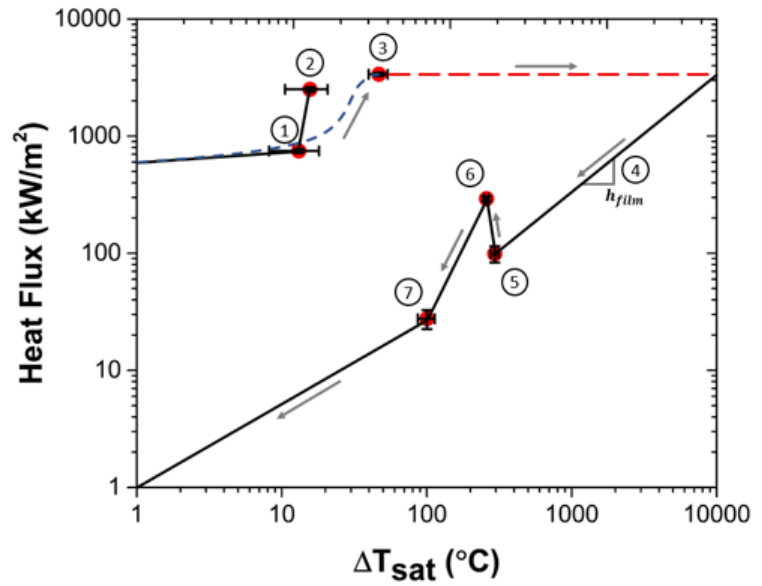

(b)

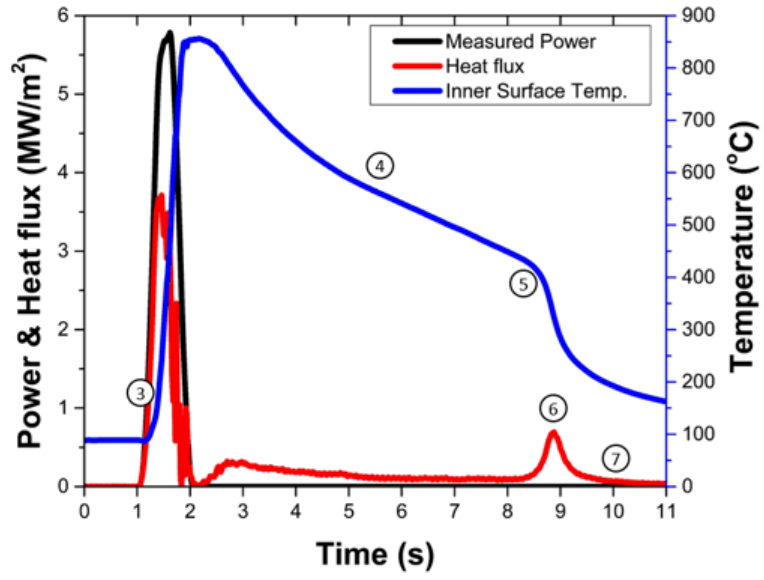

Figure 18. Fe-13Cr-6Al alloy: (a) obtained boiling curves for steady-state and transient flow boiling

(Mass flow of $300 \mathrm{~kg} / \mathrm{m}^{2} \mathrm{~s}$; quality at -0.0068 ); (b) typical experimental measurements and postprocessed data of transient pulsed power input

\subsection{Implications for Current Zirconium-based alloy Claddings}

Recent interests in cladding-dependent CHF in LWRs have been primarily triggered by ATF cladding research. It is noteworthy that the current reactor design and safety analyses widely use the CHF lookup table or W-3 correlations [39], all of which were developed with steel materials. This means that a DNB margin evaluated by the current analyses is not specific to the zircaloy cladding. Hence, quantification of the difference (if any) between the lookup table or W-3 correlations and zircaloy cladding materials should be preceded for the immediate engineering impact. Without this link established, any direct comparisons between Zircaloy and ATF cladding materials hold limited significance to current design and safety analyses (Fig.19).

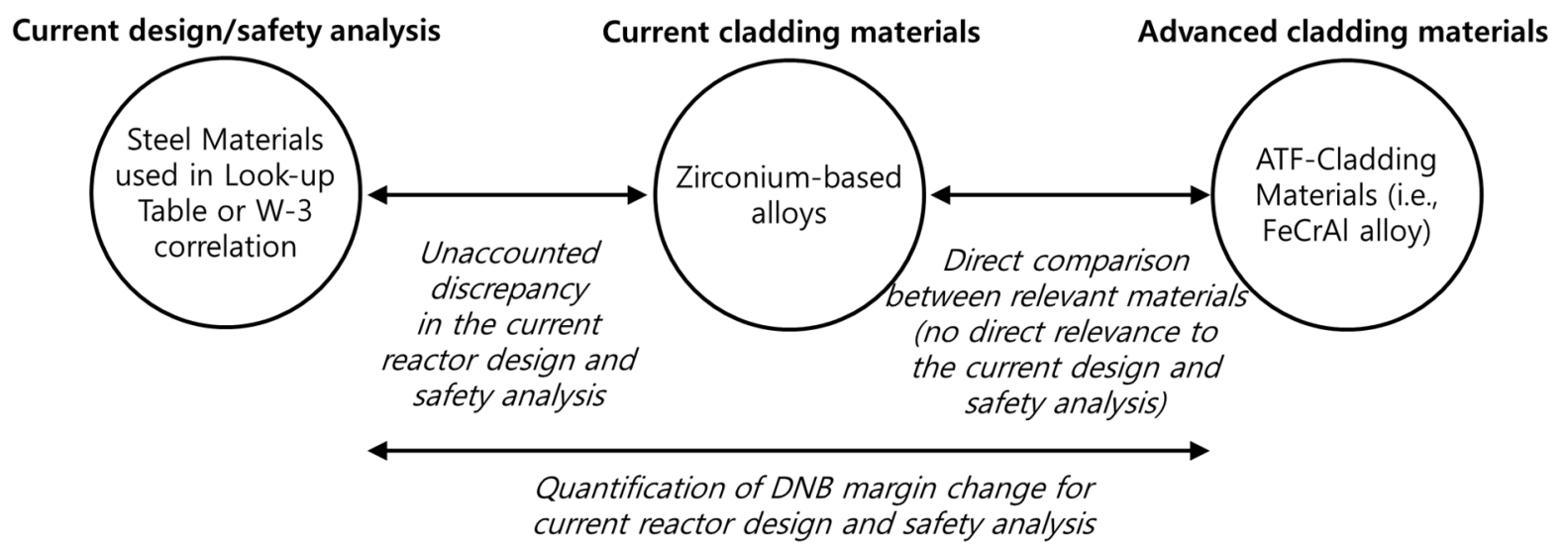


Figure 19. CHF Comparison Schematics and Implications for each Comparison

This study demonstrates Fe-13Cr-6Al alloy and Zircaloy-4 exhibit differences from the lookup table CHF prediction by $13 \%$ increase, and $16 \%$ decrease, respectively. The apparent agreement of Inconel 600 and the lookup table with the lower $8 \%$ difference supports that the observed $\mathrm{CHF}$ differences for $\mathrm{FeCrAl}$ and Zircaloy are real, and illuminates the current situation of DNB evaluation without consideration of material type.

\section{CONCLUSION}

In this study, steady and transient (heating rate of $685^{\circ} \mathrm{C} / \mathrm{s}$ ) internal-flow CHF experiments were conducted under atmospheric pressure at a fixed inlet temperature $\left(40^{\circ} \mathrm{C}\right.$ or $\left.60^{\circ} \mathrm{C}\right)$ and mass flow $(300 \mathrm{~kg} /$ $\mathrm{m}^{2} \mathrm{~s}$ ) on Fe-13Cr-6Al alloy, Zircaloy-4 and Inconel 600 tubes. By applying an identical reference flow environment for all tested materials, consistent comparisons were made. Multiple experiments were performed on the same specimen to investigate the effect of surface characteristic changes (i.e., roughness, wettability, and oxide scale morphology) due to the occurrence of CHF. We hypothesize some reasons for the different CHF measurements using fundamental heat transfer and material properties. For the tested flow condition, steady-state boiling curves and a transient boiling curve was obtained from experimental measurements for all three tested materials, and $\mathrm{Fe}-13 \mathrm{Cr}-6 \mathrm{Al}$ alloy, respectively.

The key findings are as follows:

(1) Despite the notable changes of wettability, roughness, and oxide layer characteristics upon the occurrence of CHF, flow boiling CHF sensitivity to these parameters was not observed throughout repeated experiments for tested materials. This result suggests that the effect of surface properties on the flow boiling CHF is limited in the tested flow conditions.

(2) In the steady-state flow boiling condition, Fe-13Cr-6Al alloy demonstrates a $22 \%$ and $14 \%$ increase in CHF compared to Zircaloy-4 and Inconel 600, respectively. Compared to the 2006 Groeneveld CHF lookup table, Fe-13Cr-6Al alloy gives a 13\% increase in the tested flow boiling condition. This result may speak to the possibility of increasing the DNB margin for FeCrAl in PWRs. 
(3) The Fe- $13 \mathrm{Cr}-6 \mathrm{Al}$ transient $\mathrm{CHF}$ at the heating rate of $685^{\circ} \mathrm{C} / \mathrm{s}$ are $39 \%$ and $23 \%$ higher than the lookup table prediction and the steady-state condition experimental result, respectively. This result implies the need for the boiling curve correction for the mechanistic temperature prediction of nuclear fuel cladding subject to fast transients, including RIA. As a practical demonstration, key parts of the transient boiling curve were constructed using experimental measurements.

(4) Material properties are considered primarily responsible for the observed CHF differences among the tested materials. Surface thermal economy parameter $\left(\frac{\left(\rho c_{p}\right)^{3 / 2}}{\sqrt{k}}\right)$, which is the ratio of the ability to dissipate heat at the surface to the ability to draw heat to the cold spot via solid conduction, is proposed to relate the observed variation between materials. This parameter is argued to relate to a material's ability to avoid an irreversible dry spot formation and provides a consistent explanation for the observed CHF differences.

(5) The presented material-dependent CHF naturally leads to revisiting current CHF correlations and lookup tables, all of which were developed with steel-based materials. The apparent disagreement of Zircaloy-4 CHF with both the look up table prediction and Inconel 600 shows the limitation of DNB evaluations made without respect to a particular cladding material.

\section{ACKOWLEDGEMENT}

This study is carried out in the Nuclear Engineering Department at University of New Mexico. The authors thankfully acknowledge the financial support from Department of Energy by NEUP program award 17-12688 and IRP program award DE-NE-0008531. 


\section{REFERENCES}

[1] S.J. Zinkle, K.A. Terrani, J.C. Gehin, L.J. Ott, L.L. Snead, Accident tolerant fuels for LWRs: a perspective, Journal of nuclear materials, 448 (2014) 374-379

[2] K.A. Terrani, T.M. Karlsen, and Y. Yamamoto, Input correlations for irradiation creep of FeCrAl and SiC based on in-pile Halden test results, Technical Report ORNL/TM-2016/191, Oak Ridge National Laboratory (2016).

[3] K.A. Gamble, T. Barani, D. Pizzocri, J.D. Hales, K.A. Terrani, G. Pastore, An investigation of FeCrAl cladding behavior under normal operating and loss of coolant conditions, Journal of nuclear materials, 491 (2017) 55-66

[4] M.B. Cinbiz, N.R. Brown, R.R. Lowden, M.N. Gussev, K.D. Linton, K.A. Terrani, Report on Design and Failure Limits of $\mathrm{SiC} / \mathrm{SiC}$ and FeCrAl ATF Cladding Concepts under RIA (No. ORNL/LTR2018/521). Oak Ridge National Lab.(ORNL), Oak Ridge, TN (2018)

[5] N.M. George, K.A. Terrani, J. Powers, A. Worrall, I. Maldonado, Neutronic analysis of candidate accident-tolerant cladding concepts in pressurized water reactors. Annals of Nuclear Energy, 75 (2015) 703-712.

[6] N.R. Brown, M. Todosow, A. Cuadra, Screening of advanced cladding materials and UN-U 3 Si 5 fuel. Journal of Nuclear Materials, 462 (2015) 26-42.

[7] N.R. Brown, A.J. Wysocki, K.A. Terrani, K.G. Xu, D.M. Wachs, The potential impact of enhanced accident tolerant cladding materials on reactivity initiated accidents in light water reactors. Annals of Nuclear Energy, 99 (2017) 353-365.

[8] J.R. Burns, N.R. Brown, Neutron cross section sensitivity and uncertainty analysis of candidate accident tolerant fuel concepts. Annals of Nuclear Energy, 110 (2017) 1249-1255.

[9] Y. Lee, J.I. Lee, H.C. No, Mechanical analysis of surface-coated zircaloy cladding, Nuclear engineering and technology 49 (2017) 1031-1043.

[10] Y. Lee, H.C. No, J.I. Lee, Design optimization of multi-layer silicon carbide cladding for light water reactors, Nuclear engineering and design, 311 (2017) 213-223.

[11] Y. Lee, H.S. Kim, H.C. No, Failure probabilities of SiC clad fuel during a LOCA in Public Acceptable Simple SMR (PASS). Nuclear engineering and design, 292 (2015) 1-16.

[12] Y. Lee, M.S. Kazimi, A structural model for multi-layered ceramic cylinders and its application to silicon carbide cladding of light water reactor fuel. Journal of nuclear materials, 458 (2015) 87-105. [13] C. Han, P. Griffith, The mechanism of heat transfer in nucleate pool boiling, A technical report, Massachusetts Institute of Technology (1962).

[14] Y.Y. Hsu, On the size range of active nucleation cavities on a heating surface, Journal of heat transfer, (1962) 207-213 
[15] V. Bessiron, Modelling of clad-to-coolant heat transfer for RIA applications, Journal of nuclear science and technology. 44 (2007) 211-221.

[16] V. Bessiron, T. Sugiyama, T. Fuketa, Clad-to-coolant heat transfer in NSRR experiments, Journal of nuclear science and technology. 44 (2007) 723-732.

[17] R. Visentini, C. Colin, P. Ruyer, Experimental investigation of heat transfer in transient boiling, Experimental thermal and fluid science 55 (2014) 95-105.

[18] G. Su, M. Bucci, T. McKrell, J. Buongiorno, Transient boiling of water under exponentially escalating heat inputs. Part II: flowboiling, International journal of heat and mass transfer. 96 (2016) 685698.

[19] M. Liu, N.R. Brown, K.A. Terrani, A. Ali, E.D. Blandford, D.M. Wachs, Potential impact of accident tolerant fuel cladding critical heat flux characteristics on the high temperature phase of reactivity initiated accidents, Annals of nuclear engineering, 110 (2017) 48-62.

[20] D.C. Groeneveld, J.Q. Shan, A.Z. Vasic, L.K.H. Leung, A. Durmayaz, J. Yang, S.C. Cheng, A. Tanase, The 2006 CHF look-up table, Nuclear engineering and design, 237 (2007) 1909-1922.

[21] A. Ali, J. Gorton, N.R. Brown, K.A. Terrani, C. Jensen, Y. Lee, E.D. Blandford, Surface wettability and pool boiling critical heat flux of accident tolerant fuel cladding FeCrAl alloys, Nuclear engineering and design, 338 (2018) 218-231.

[22] V. K. Dhir and S. P. Liaw, Framework for a unified model for nucleate and transition pool boiling, Journal of Heat Transfer, 111 (1989) 739

[23] S.G. Kandlikar, Critical heat flux in subcooled flow boiling - An assessment of current understanding and future directions for research, Multiphase Science and Technology, 13 (2001) 105-130. [24] H. O’Hanley, C. Coyle, J. Buongiorno, T. McKrell, L.W. Hu, M. Rubner, R. Cohen, Separate effects of surface roughness, wettability, and porosity on the boiling critical heat flux, Applied physics letters, 103 (2013) 024102

[25] H.S. Ahn, H. Kim, H. Jo, S.H. Kang, W.P. Chang, M.H. Kim, Experimental study of critical heat flux enhancement during forced convective flow boiling of nanofluid on a short heated surface, international journal of multiphase flow, 36 (2010) 375-384

[26] M.H. Lee, H. Heo, I.C. Bang, Effect of thermal activity on critical heat flux enhancement in downward-hemispherical surface using graphene oxide coating, International journal of heat and mass transfer, 127 (2018) 1102-1111

[27] G.H. Seo, G. Jeun, S.J. Kim, Enhanced pool boiling critical heat flux with a FeCrAl layer fabricated by DC sputtering, International journal of heat and mass transfer, 102 (2016) 1293-1307 
[28] Brown, N.R., Todosow, M. and Cuadra, A., 2015. Screening of advanced cladding materials and UN-U 3 Si 5 fuel. Journal of Nuclear Materials, 462, pp.26-42

[29] Brown, N.R., Wysocki, A.J., Terrani, K.A., Xu, K.G. and Wachs, D.M., 2017. The potential impact of enhanced accident tolerant cladding materials on reactivity initiated accidents in light water reactors. Annals of Nuclear Energy, 99, pp.353-365.

[30] Y. Yamamoto, B.A. Pint, K.A. Terrani, K.G. Field, Y. Yang, L.L. Snead, Development and property evaluation of nuclear grade wrought $\mathrm{FeCrAl}$ fuel cladding for light water reactors, Journal of nuclear materials, 467 (2015) 703-716

[31] K.G. Field, M.A. Snead, Y. Yamamoto, K.A. Terrani, Handbook on the Material Properties of FeCrAl Alloys for Nuclear Power Production Applications - Nuclear Technology Research and Development, ORNL/TM-2018/186, M3FT-17OR020203031, (2018)

[32] American Society of Testing Materials (ASTM), Standard Practice for Surface Wettability of Coatings, Substrates and Pigments by Advancing Contact Angle Measurement, Designation: D7334 - 08 (2013)

[33] T.L. Bergman, A.S. Lavine, F.P. Incropera, D.P. Dewitt, Fundamentals of heat and mass transfer, seventh edition, John Wiley \& Sons, Inc, Hoboken, NJ, USA, 2011

[34] M. Arik, A. Bar-Cohen, Effusivity-Based Correlation of Surface Property Effects in Pool Boiling CHF of Dielectric Liquids, International Journal of Heat and Mass Transfer, 46 (2003) 3755-3764

[35] I. Golobič, A.E. Bergles, Effects of Heater-Side Factors on the Saturated Pool Boiling Critical Heat Flux, Experimental Thermal and Fluid Science, 15 (1997) 43-51

[36] G. Guglielmini, E. Nannei, On the Effect of Heating Wall Thickness on Pool Boiling Burnout, International Journal of Heat and Mass Transfer, 19(1976) 1073-1075

[37] I.I. Gogonin, "Influence of the Thickness of a Wall and of its Thermophysical Characteristics on the Critical Heat Flux in Boiling," Journal of Engineering Physics and Thermophysics, 82 (2009) 6 [38] W. Jäger, V.H.S. Espinoza, A. Hurtado, Review and proposal for heat transfer predictions at supercritical water conditions using existing correlations and experiments, Nuclear engineering and design, 241 (2011) 2184-2203

[39] VIPRE-01: A Thermal-Hydraulic Code for Reactor Cores, Vol.2: User's Manual (Rev.2), Appendix D: CHF and CPR Correlations. NP-2511-CCM-A, Research Project 1584-1, Prepared by Batelle, Pacific Northwest Laboratories for Electric Power Research Institute, 1985 